\title{
Rapid identification information and its influence on the perceived clues at a crime scene: an experimental study
}

\author{
Madeleine de Gruijter, Claire Nee \& Christianne J. de Poot
}

\begin{abstract}
Crime scenes can always be explained in multiple ways. Traces alone do not provide enough information to infer a whole series of events that has taken place; they only provide clues for these inferences. CSIs need additional information to be able to interpret observed traces. In the near future, a new source of information that could help to interpret a crime scene and testing hypotheses will become available with the advent of rapid identification techniques. A previous study with CSIs demonstrated that this information had an influence on the interpretation of the crime scene, yet it is still unknown what exact information was used for this interpretation and for the construction of their scenario. The present study builds on this study and gains more insight into (1) the exact investigative and forensic information that was used by CSIs to construct their scenario, (2) the inferences drawn from this information, and (3) the kind of evidence that was selected at the crime scene to (dis)prove this scenario. We asked 48 CSIs to investigate a potential murder crime scene on the computer and explicate what information they used to construct a scenario and to select traces for analysis. The results show that the introduction of rapid ID information at the start of an investigation contributes to the recognition of different clues at the crime scene, but also to different interpretations of identical information, depending on the kind of information available and the scenario one has in mind. Furthermore, not all relevant traces were recognized, showing that important information can be missed during the investigation. In this study, accurate crime scenarios where mainly build with forensic information, but we should be aware of the fact that crime scenes are always contaminated with unrelated traces and thus be cautious of the power of rapid ID at the crime scene.
\end{abstract}

Keywords:

Crime scene investigation

Rapid identification

Trace recognition

Scenario construction

Evidence

Cognitive bias 


\subsection{Introduction}

The objective of crime scene investigations is to make a reconstruction of the event that has taken place at the scene of a crime and find evidence to prove or disprove formulated hypotheses, contributing to the fundamental questions of an investigation. This is a difficult task, because only the consequences of a crime are visible and multiple interpretations can explain them. Crime Scene Investigators (CSIs) have to perceive the visible or latent traces that are left at the crime scene, and have to infer their causes [1,2]. Traces alone do not provide enough information to infer a whole series of events that has taken place; they only provide clues for these inferences. Interpretations are necessary in order to give meaning to these clues, to link them to actions and to construct a story about the crime. As multiple explanations are always possible for the observed traces, other information, i.e. prior knowledge, will be used to make interpretations. This can be information coming from police-officers at the scene, witness statements or victim information, from forensic information and from the experiential knowledge of CSIs.

Due to technological developments, a new source of information that can be used to interpret the crime scene may soon become available: identification information based on rapid trace analyses. The development of new rapid identification technologies will make it possible to analyse traces and compare them with databases, e.g. for DNA-traces and fingerprints [3-5]. CSIs will then be able to receive identification (ID) information about the persons that left the traces while still conducting the investigation. A previous study showed that this information influences the interpretation of the crime scene [6]. CSIs were asked to construct a scenario after they investigated a crime scene. All participants received identical investigative information, mostly witness statements, and half of the participants received rapid identification information coming from traces found at the crime scene. This study demonstrated that ID information had an influence on the interpretation of the crime scene by showing differences in the scenarios that were constructed depending on the information that was available to the participants. The present study builds on this by elaborating on the specific influence of investigative and forensic ID information on the construction of scenarios. i.e. the inferences drawn from different kinds of information, and the kind of evidence that was selected at the crime scene to prove scenarios.

\subsection{Interpreting the scene and searching for evidence}

In order to reconstruct the crime that took place it is necessary to formulate hypotheses based on observations at the crime scene. These hypotheses need to be combined and a coherent and plausible scenario should be created to make sense of all the available information [7-9]. Interpreting a crime scene is a difficult task, because the crime scene only shows the consequences of the actions that occurred at the scene, and multiple explanations will fit with the traces [10]. In order to discriminate between different explanations of the observed traces, and different scenarios of what has happened at the scene, CSIs need to seek for evidence that can prove or disprove these scenarios [11,12].

The investigation starts with an observation of the scene, the perception of traces and then drawing inferences about the causes of these traces. In order to make inferences, context and general knowledge is needed [13]. Generally, a bloodstain alone has no value. Of course, some bloodstains will immediately show their significance while others are less obviously related with a criminal event, but value needs to be attached to it by considering the context in which the stain is found and by using experiential knowledge. The context can be determined based on the situation at the crime scene, but also on information coming from police officers. Police officers often brief the CSIs about the situation (e.g. about the victim, the crime scene, any witnesses) before the CSIs start their investigation at the scene. This information, together with experiential knowledge, can be used to form hypotheses and decide on the potentially relevant traces observed at the scene [14]. 
Let us present an example of such interaction between such factors. CSIs are called to a crime scene and are told they have to investigate a burglary scene and that a witness heard smashing glass during the crime - police information. When a bloodstain is found next to a smashed window, CSIs infer that the offender must have injured himself and left blood. The context in which the stain is found (next to a smashed window -forensic information- at a burglary scene-police information) together with existing knowledge of the behaviour of burglars and the traces they leave due to this behaviour (experience) are used to find explanations for this observation. These factors are used to distinguish relevant from irrelevant traces and to build hypotheses about what has happened. Using context and experiential knowledge refers to top-down processing, which allows efficient and effective processing of the bottom-up data, i.e. the blood stain $[15,16]$. Interpreting information in order to produce hypotheses about the crime is also known as the transfer from raw information to intelligence [17].

Top-down processing is possible due to the development of schemas. In general, experts create patterns representing the most important characteristics of their task based on experience in their field. These schemas help to structure large amounts of data in order to understand a situation quickly [18]. Experts tend to focus their attention on relevant cues from a case history and implicitly use their schemas during a search for and the interpretation of information [19-21]. Klein [22] also describes how experts recognize cues from a mental repertoire of patterns. Their experience gives them a heightened situational awareness of which cues are relevant and what information can be ignored. More experience results in richer schemas and thus more numerous, inter-connected 'recipes' about where to search for traces given different crime scenes [20].

So both context information and expertise help with the interpretation of information, but both factors can also hinder the investigation. When context information is incorrect, it can lead to incorrect interpretations $[14,15,23]$. Furthermore, when experts have been doing the job for too long and have become over-confident, expertise may cause premature closure and mistakes are made [24]. For example, common characteristics of the crime scene that are wrongly interpreted consequently lead to a wrong categorisation of the scene and its traces (e.g. the bloodstain was not left by the offender, but CSIs missed the clues leading to this conclusion as they were confident of the common idea that offenders can leave blood when they smash windows).

So observed traces can be explained in various ways and the most likely explanation should be found. In order to discriminate between different explanations CSIs can search for evidence. A common strategy used by people is to search for evidence that can be used for verification or confirmation of their ideas [11,12]. Equally important however, is an attempt to falsify and search for evidence that contradicts an idea. Ideally, you would think of multiple hypotheses and try to find information that can discriminate between these hypotheses $[11,25]$. For example, when you assume only the victim got injured and thus a bloodstain found at the scene is left by the victim, you should also consider the possibility that the offender got injured and lost blood. Analysing the trace could falsify one of your hypotheses. The hypotheses CSIs have in mind determine to a great extent the selection of evidence and the kind of information that is considered relevant for testing them.

\subsection{Identification information}

A new source of information that could help interpreting a crime scene and testing hypotheses becomes available with the development of rapid identification techniques. Currently, information about the source of traces is not available during the crime scene investigation itself, because of the current turn-around times for traces [26,27]. When rapid identification technologies will be introduced, the analysis of DNA-traces or fingermarks and their comparison with databases can be done within hours and thus be transferred to the crime scene. Information about the sources can then be used in the construction and verification of scenarios. Such rapid availability of identification 
information may be very useful because provisional scenarios can be tested and, if necessary, adjusted during the investigation itself. Rapid feedback of results will speed up the investigation and offenders may more quickly be identified. A risk however may be that database-matches may have too much influence on the investigation with the consequence that scenarios will be based on database-matches without considering the relevance of the traces that did provide a match [6]. Generally, forensic evidence is seen as more objective because it is based on science [28]. However, human errors can still be of influence since the evidence needs to be interpreted to create a story and human decision making is prone to errors $[29,30]$. Our previous study showed that ID information had considerable influence on the interpretation of the scene, when both ID information as well as investigative information were available at the crime scene. CSIs who received investigative information as well as rapid ID information constructed different scenarios than CSIs who only received investigative information. This finding suggests that the availability of rapid ID information can change the interpretation of the crime scene when this information is not just a confirmation of the investigative information, but suggest a different explanation of the crime scene.

The aim of the present study is to investigate in more detail how ID information influences the construction of scenarios by elaborating on these findings. More specifically, this study will analyse more precisely how three types of information, namely (1) investigative, (2) crime scene information and (3) ID information, of which the latter two together represent forensic information, is used by CSIs to build scenarios, to draw inferences, and to select forensic evidence. We will further analyse the data obtained in our previous study by analysing the influence of the availability of rapid ID information on the kind of information CSIs used to form their scenarios, the inferences they drew from these clues and the evidence they selected for analysis. Based on our former study we assume that the availability of ID information leads to the use of more forensic information and different interpretations of the scene. Furthermore, based on the common tendency to seek for confirmation, we hypothesize that CSIs will select evidence to confirm their most provisional scenario instead of looking for falsification. 


\subsection{Method}

The method section below outlines the scenarios we constructed for this study, the stimulus material that was provided to the participants, the design of the study and an explanation of the data scoring procedure. As this study is an elaboration of the study of De Gruijter et al. [6], the method and datacollection are identical to these sections described in that paper. However, our previous paper studied two questions: (1) the influence of the timing of ID information on the interpretation of the crime scene and (2) the importance of receiving a database-match. The present paper is an elaboration of only the first question, so for the section explaining the design to answer question two we will limit ourselves to a summary. In this method section, we will mainly focus on those parts of the method and the data collection that are necessary to understand the goal of this study, the analyses we conducted and the results we want to present. We will elaborate on those aspects not fully described in our previous study and recite the aspects necessary to understand the present study.

\subsection{Scenarios}

In order to be able to study the influence of the available investigative information, crime scene information and ID information on the interpretation of the crime scene we created an ambiguous crime scene, based on a real crime case. We constructed this crime scene in collaboration with crime scene investigators. There were two possible main scenarios of which an aggravated burglary scenario was the ground truth.

\subsubsection{The ground truth - burglary scenario}

Two burglars, Ayden Roberts and John Campbell, killed a woman named Valerie by strangulation during a break in at her house. Valerie and her husband Steve got into a heated argument earlier that morning after Valerie admitted she was having an affair. Both of them left the house after the fight. In the meantime, the burglars entered their house. Valerie caught the burglars red handed when she came home. Ayden and John panicked and Valerie was strangled. Steve came home and found Valerie and called an ambulance. She was brought to the hospital where she died in intensive care. Colleagues at the hospital told the police that Valerie had unusual red marks on her neck. This story is the ground truth in our study.

\subsubsection{Alternative scenario - domestic homicide}

The scene was intentionally set up in an ambiguous way in order to thoroughly examine the research question and test the influence of ID information on the interpretation of the scene. In addition to the ground truth there is also a possible alternative interpretation of a domestic homicide in which Steve, the husband, killed his wife Valerie that fitted with the traces at the crime scene. The start of this alternative story is similar as the ground truth. Steve and Valerie had a heated argument in the morning and both of them left after the fight. Valerie came home first, followed by Steve. He strangled Valerie in a rage. Afterwards, he staged a burglary by opening the drawers and cupboards and called the ambulance.

\subsection{Information provided to participants}

All participants received information about the crime. This information could come from two different sources of information, namely from people who were questioned (investigative information) or from traces and other information available at the crime scene (forensic information). Forensic information can be divided into information perceived from the crime scene (crime scene information) and identification information that was obtained by the rapid analysis of twelve preselected traces (ID information). 


\subsubsection{Investigative information}

All participants received identical investigative information at the start of their investigation. The information contained preliminary findings in the investigation, including a witness statement from the husband of the victim (Steve), from the neighbour (Trudy), from a friend of the victim (Jessica) and a friend of the husband (Simon). Table 1 shows a summary of the content of the statements. Altogether this information suggested a scenario in which husband Steve is a potential suspect.

Table 1: summary of the investigative information provided to all participants.

\begin{tabular}{|c|c|c|c|c|c|}
\hline $\begin{array}{l}\text { Statement made } \\
\text { by: }\end{array}$ & \multicolumn{5}{|c|}{ Kind of information given in statement } \\
\hline Husband Steve & $\begin{array}{c}\text { Found his wife } \\
\text { when he arrived } \\
\text { home and called } \\
\text { ambu at } 6.15\end{array}$ & $\begin{array}{l}\text { They had a fight } \\
\text { in the morning. } \\
\text { Steve has } \\
\text { scratches in his } \\
\text { face from the } \\
\text { fight }\end{array}$ & $\begin{array}{l}\text { He went to the } \\
\text { pub with friend } \\
\text { Simon and drank } \\
\text { beers. }\end{array}$ & $\begin{array}{l}\text { He walked } \\
\text { around after the } \\
\text { pub, before he } \\
\text { came home }\end{array}$ & $\begin{array}{l}\text { Front door and } \\
\text { drawers were } \\
\text { open when he } \\
\text { came home }\end{array}$ \\
\hline Neighbour Trudy & $\begin{array}{l}\text { She heard } \\
\text { shouting in } \\
\text { morning and } \\
\text { afternoon }\end{array}$ & $\begin{array}{l}\text { Saw husband and } \\
\text { wife leave } \\
\text { separately after } \\
\text { shouting in the } \\
\text { morning }\end{array}$ & $\begin{array}{c}\text { She saw an } \\
\text { unknown man } \\
\text { walking in the } \\
\text { street, but did not } \\
\text { see anyone } \\
\text { strange go inside }\end{array}$ & $\begin{array}{l}\text { Husband and } \\
\text { wife have a rich } \\
\text { social life and } \\
\text { have a lot of } \\
\text { people in their } \\
\text { house. }\end{array}$ & $\begin{array}{c}\text { She heard } \\
\text { husband and wife } \\
\text { shouting more } \\
\text { often lately }\end{array}$ \\
\hline Friend Jessica & $\begin{array}{l}\text { Valerie came to } \\
\text { Jessica that } \\
\text { morning and told } \\
\text { her about the } \\
\text { fight. }\end{array}$ & $\begin{array}{c}\text { Husband Steve } \\
\text { found out his } \\
\text { wife Valerie had } \\
\text { an affair. They } \\
\text { had a serious } \\
\text { quarrel about it, } \\
\text { ending in a fierce } \\
\text { battle and a mess } \\
\text { in the living } \\
\text { room }\end{array}$ & $\begin{array}{l}\text { Valerie looked } \\
\text { scared }\end{array}$ & & \\
\hline Friend Simon & $\begin{array}{c}\text { He had beers in } \\
\text { the pub with } \\
\text { Steve until } 4.30 \\
\text { pm. }\end{array}$ & $\begin{array}{l}\text { He does not } \\
\text { know if Steve } \\
\text { went directly } \\
\text { home or not. }\end{array}$ & & & \\
\hline
\end{tabular}

\subsubsection{Forensic information}

Besides investigative information there were two sources of forensic information: the crime scene the participants could observe themselves using a 3D and identification information obtained by rapid analyses of twelve pre-selected traces.

\subsubsection{The crime scene}

We created an ambiguous crime scene that matched the burglary scenario as well as the domestic homicide scenario. The crime scene was created in the Netherlands in collaboration with Dutch expert crime scene investigators. The crime scene was based on a real case ensuring that traces were left at realistic places which makes the investigation as realistic as possible and therefore of more value to the end-user. We created the mock crime scene of the homicide case in one of the houses of the Dutch police academy, that are normally used for training purposes. In order to be able to collect enough data we photographed the crime scene with a panoramic camera which produced a 3D computer coverage of the scene. In this way, participants did not have to be physically present at the scene but could investigate it from behind the computer. They could navigate through the scene and zoom in 
and out. In addition, participants were provided more detailed photographs of the scene on paper. Figure 1 shows photos of the scene and the outlook of the panoramic scene on the computer.
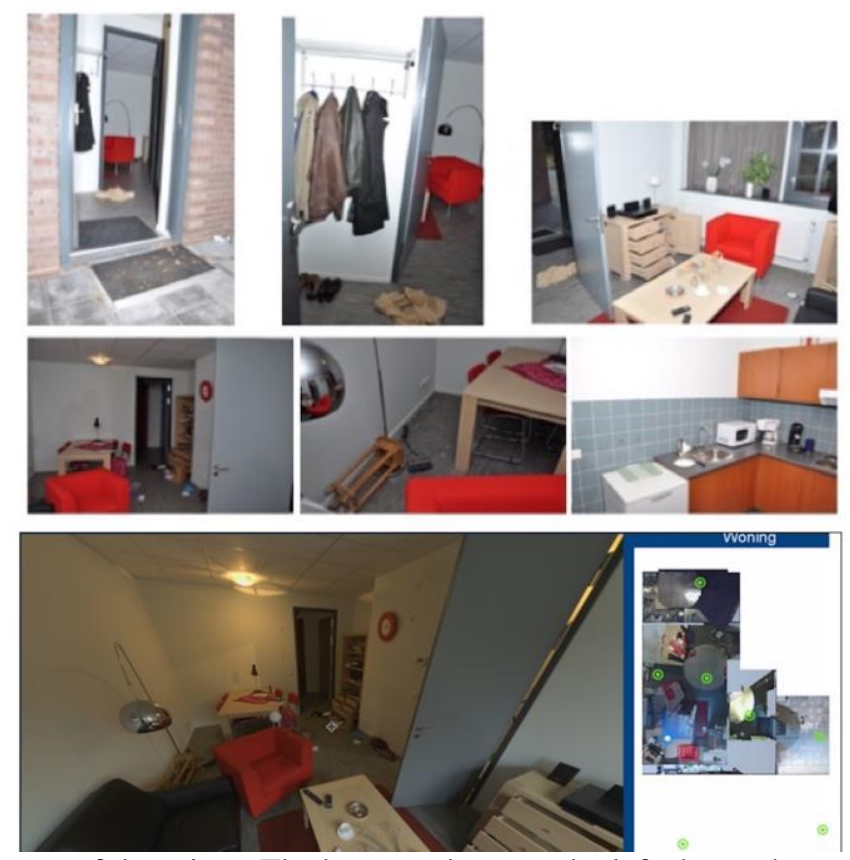

Figure 1: photos of the scene of the crime. The bottom photo on the left shows the outlook of the scene on the computer, the picture on the bottom right shows the plan of the house from a view from above. The green dots can be clicked on to view the house from another angle.

\subsubsection{Identification information}

It was suggested to participants that twelve traces or items from the scene were analysed with rapid identification technologies. Six of those traces were left by one of the burglars and six by Valerie or Steve. Burglar 1 left traces on a cigarette butt outside, the window of the house and the scarf inside the house. Burglar 2 left traces on a beer can outside, the post flap in the front door and on the shoulder bag inside the house. The other six traces corresponded with Valerie or Steve and were obtained from regular items on the coffee table, blood on a tissue and both of them were also found on the shoulder bag and scarf. The shoulder bag and the scarf were potential murder weapons present at the scene.

The information that these traces provided suggested a scenario with the potential involvement of two other persons (i.e. the burglars), but the ID information also fit the alternative domestic homicide scenario as the traces left by the burglars are not strongly crime related and could be interpreted as being left during another occasion.

\subsection{Design of the study}

The experiment comprised a 2 (rapid ID information: before; after) x 2 (database match: with burglar 1 , no match with burglar 2; match with burglar 2, no match with burglar 1) between participants design. ${ }^{1}$ For this paper we will elaborate on factor 1 (rapid ID information) and summarize factor 2 (database match) as this factor was used for answering the second question in our former paper. A summary is sufficient for the purpose of the current paper.

\footnotetext{
1 The design was tested in a pilot study with 64 university students. The results showed that the research questions could be answered by the manipulations in the present design.
} 


\subsubsection{Factor 1: rapid info}

Half of the participants received analysis results of twelve pre-selected traces (group 2: ID). They were told that these traces were analysed with rapid identification technologies and obtained profiles were searched against the National DNA database (NDNAD). Obtained fingermarks were searched against the database for fingerprints (IDENT1). These participants received this information at the start of their investigation together with the investigative information, before they answered the questions. They were therefore able to use the identification information in their scenario formation. The other half did not receive this information (group 1: NO ID). Hence, they had to write a scenario based on the crime scene information and the investigative information alone, without ID information.

\subsubsection{Factor II: database-match}

The second factor concerns which of the two burglars is supposed to be included in the NDNAD, either burglar 1 or burglar 2. This means that participants in the group with ID information received a match with either burglar 1 or burglar 2 on traces left by this burglar and a non-match for traces having been left by the other burglar. For the traces left by the unknown burglar they received the information that no match was found and the trace was left by unknown person $\mathrm{X}$. This factor was randomly assigned to participants in group 2 (ID info). For a full description of this factor, see De Gruijter, et. al., [6].

\subsection{Participants}

A total of 48 CSIs from eight police stations in four different regions in England participated in this study. They had on average spent 12 years in a forensic department. The majority worked as a CSI $(75 \%)$. The other $25 \%$ worked as a crime scene manager or held a similar kind of function. There was no difference in age, police force, education, gender and experience between the conditions.

\subsection{Procedure}

The sessions for the CSIs were held at the police stations in England where they were located. All participants received a leaflet with information about the research, an informed consent form and they were briefed about the investigation. Participants were instructed to imagine that they had to conduct a forensic investigation. It was explained that the crime scene was on the computer and the experimenter demonstrated to the participants how to navigate the environment on the outside of the house, so as not to prime their responses inside. They were explicitly instructed to process the crime scene as much possible as if it were a real crime scene. Witness statements and ID information were given both on the computer and on paper. The experiment consisted of three phases. All participants were asked to:

1. Write one most likely provisional scenario about what had happened;

2. Explicate the kind of information used to construct this scenario;

3. Select a maximum of six traces for analysis.

There was no time limit for the participants.

Our previous paper studied the influence of the timing of ID information on the interpretation of the crime scene and the importance of receiving a database-match. The present paper investigates how ID information influences the kind of information that was used to construct a scenario and the selection of traces for verifying the scenario. Figure 2 shows the design and procedure of the present study. 


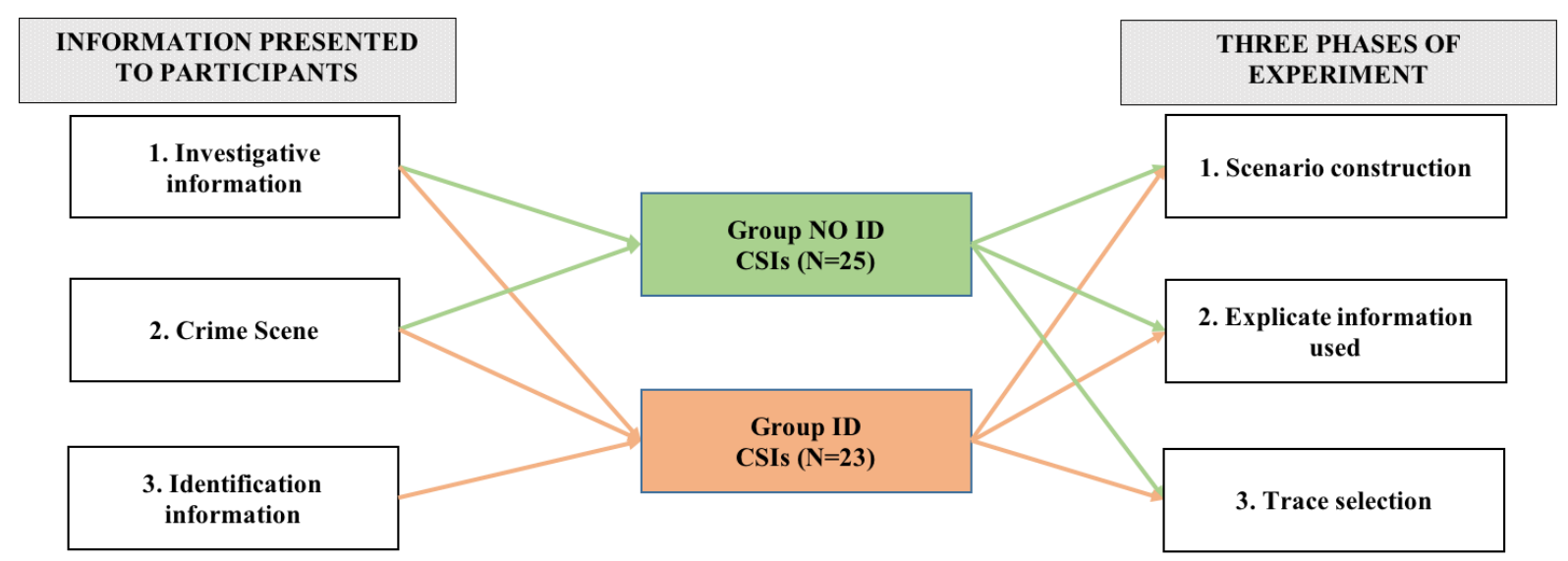

Figure 2: design and procedure of the experiment.

\subsection{Data scoring}

For all three responses of the participants (1. scenario, 2. explication on information used and 3. traces selected) the researchers coded the answers.

1. The scenarios of the participants were analyzed and classified in terms of the offender. As the investigative information pointed to the involvement of the husband while the ID information pointed to the possible involvement of other persons, the scenarios formulated by participants were distinguished into two categories with respect to the perpetrator: "scenarios in which the husband is the perpetrator" and "other scenarios", denoted as "Domestic homicide" and "Homicide by a person not being husband Steve". Participants who wrote about a natural death/accident or made no decision are excluded from the analysis as there were so few and these decisions did not fit into the new categories.

2. In phase two, all participants were asked to explicate which information they had used to base their scenario on, and why so. We started with a list of possible pieces of information we could think of, and augmented the list with entries about information mentioned by participants, we did not think of before-hand. All pieces of information of the final list were scored whether mentioned $(0=$ not mentioned, $1=$ mentioned $)$. Subsequently, the information was grouped into (a) investigative information, consisting of all witness-statements (20 pieces of information), and (b) forensic information, consisting of all information that could be observed at the crime scene, including any injuries mentioned as well as the identification information derived from DNA- and fingermarks at the crime scene (38 pieces of information). An interrater reliability analysis on this classification procedure was performed, using the $\kappa$ statistic to determine consistency among raters. Since three raters scored the pieces of information, the mean of three kappa's is given. The mean interrater reliability for the classification into those groups was found to be $\kappa=0.90(\mathrm{p}<.001)$, which shows almost perfect agreement [31]. Additionally, all underlying reasons mentioned by participants for selecting the pieces of information were listed together with the corresponding piece of information, resulting in a list of reasons per piece of information.

3. The third assignment for the participants was to select traces for analysis to generate additional evidence to test their hypotheses about what happened at the crime scene. A similar approach was used. All possible traces were pre-conceived and completed with extra traces if needed and scored if mentioned $(0=$ not mentioned, $1=$ mentioned). Again, all underlying reasons mentioned by participants for selecting these traces were coded, per selected trace. 
Scenario construction at the crime scene

\subsection{Results}

A classification of the scenarios written by participants of group 1 (NO ID) and group 2 (ID) is shown in table $2 .^{2}$

Table 2: Classification of scenarios written by participants in terms of the offender.

\begin{tabular}{l|c|c}
$\begin{array}{l}\text { In the scenario written } \\
\text { by the subject the crime was: }\end{array}$ & \multicolumn{1}{c}{$\begin{array}{c}\text { Group 1 } \\
\text { CSIs } \\
\text { (NO ID) }\end{array}$} & $\begin{array}{c}\text { Group 2 } \\
\text { CSIs } \\
\text { (ID) }\end{array}$ \\
\hline $\begin{array}{l}\text { Domestic homicide by husband } \\
\begin{array}{l}\text { Steve } \\
\text { Aggravated burglary with } \\
\text { homicide }\end{array}\end{array}$ & 17 & 8 \\
\hline \hline Total $N$ & 4 & 11 \\
\hline
\end{tabular}

CSIs in group 1 (NO ID) mostly wrote a domestic homicide scenario (17 vs 4 producing a burglary scenario). In group ID the numbers shifted to 8 domestic homicide vs 11 burglary scenarios. The difference for CSIs between group 1 (NO ID) and 2 (ID) is significant $\chi^{2}(1)=6.42, p<.01$ (one sided), $\phi=0.40$. The ID information helped participants constructing a more accurate scenario (an aggravated burglary with homicide scenario). These results will now be further elaborated on by investigating the information participants used to construct their scenarios.

\subsection{Kind of information used}

After writing their first scenario, all participants were asked to explicate the information on which they had based their scenario. We computed percentages over the number of pieces of information that the participant used. Figure 3 shows the percentages forensic information used. ${ }^{3}$ The group without ID information (group 1: NO ID) used on average 60\% forensic information and $40 \%$ investigative information. For participants with ID information (group 2: ID), the amount of investigative info used was on average only $23 \%$. They used more forensic information (77\%). Although there is a difference in the percentage forensic information used between group 1 (NO ID) and group 2 (ID), this shows not to be significant, $\mathrm{t}(36)=-1.819, \mathrm{p}=.078$.

\footnotetext{
2 The scenarios formulated by participants were re-categorized into two categories with respect to the perpetrator. Seven participants who did not fit into these categories were excluded from the analyses. For an overview of all categories see De Gruijter, et. al. [6]

${ }^{3}$ Three participants did not mention any information and were excluded from this analysis.
} 


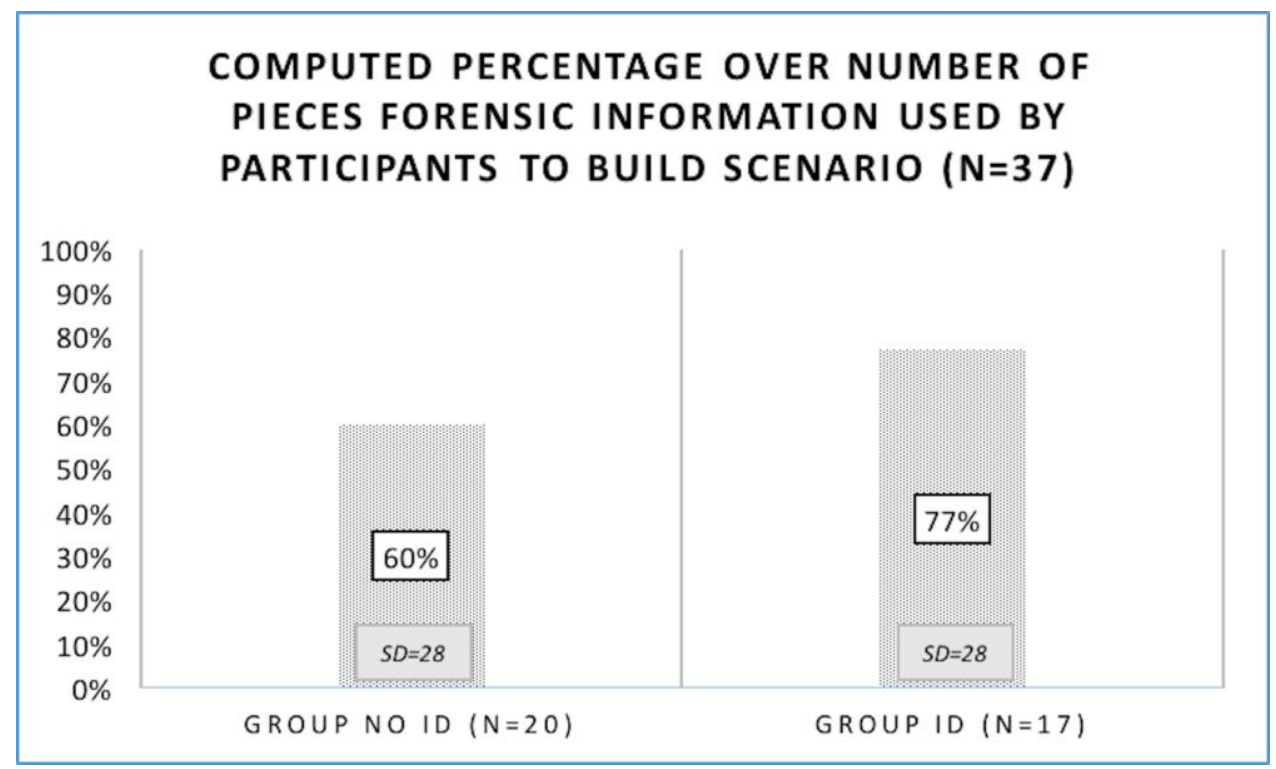

Figure 3: percentage forensic information used to build scenario.

\subsubsection{Kind of investigative information}

Participants could base their scenario on both investigative and forensic information. The mean number of pieces of investigative information mentioned is $1.7(\mathrm{SD}=1.1)$ for participants in group 1 (NO ID) with a range of $0-4$. The mean number is 0.82 ( $\mathrm{SD}=1.0)$ in group 2 (ID), with a range of $0-3$. A Mann-Whitney test indicated that the number of pieces of investigative information mentioned was significantly greater for participants in group 1 (NO ID) than for participants in group 2 (ID) (U=99.0, $\mathrm{p}=.025$ ). Due to the small amount of information used and the diversity in the kind of information, the numbers for the pieces of information are rather small and therefore any differences are difficult to demonstrate, due to low power. Table 3 shows the pieces of investigative information most mentioned by CSIs in group 1 (NO ID) and group 2 (ID).

Table 3: investigative information mostly mentioned to construct scenario in group 1 (NO ID) and 2 (ID).

\begin{tabular}{|l|c|c|c|}
\hline $\begin{array}{l}\text { Kind of investigative } \\
\text { information used to } \\
\text { construct scenario }\end{array}$ & $\begin{array}{c}\text { Group 1 } \\
\text { (NO ID) } \\
\text { (N=20) }\end{array}$ & $\begin{array}{c}\text { Group 2 } \\
\text { (ID) } \\
\text { (N=17) }\end{array}$ & P-value \\
\hline Witness statements & 3 & 2 & n.s. \\
\hline No alibi & 6 & 4 & n.s. \\
\hline Beers Steve & 3 & 1 & n.s \\
\hline Affair & 4 & 1 & n.s. \\
\hline $\begin{array}{l}\text { Heated arguments } \\
\text { Steve \& Valerie }\end{array}$ & 10 & 3 & $\chi^{2}(1)=4.22, \mathrm{p}<.05$ \\
\hline Shouting & 3 & 1 & n.s. \\
\hline
\end{tabular}

The results show no significant differences between the conditions in kind of investigative information used to construct a scenario, except the fact that Valerie and Steve had an heated argument that morning and had more of these arguments lately which was mentioned significantly more by participants without ID information $\chi^{2}(1)=4.22, p<.05$. This information was mostly used as an argument for a domestic issue as it showed that Valerie and Steve were having a bad time in their relationship. The fact that Steve had no alibi was mentioned by participants, in both conditions, who 
constructed a domestic homicide scenario. They argued that Steve had enough time to commit the crime and stage a burglary. The affair was seen as possible motive for Steve.

\subsubsection{Kind of forensic information}

Participants of group 1 (NO ID) mentioned a similar number of forensic information compared to participants of group 2 (ID) $(\mathrm{M}=2.9(\mathrm{SD}=1.9)$ vs $\mathrm{M}=3.3(\mathrm{SD}=1.7))$. The range for group 1 (NO ID) was $0-7$, for group 2 (ID) the range was 0-6. Again, the small numbers, high range and diversity in kind of information mentioned makes it difficult to demonstrate any differences. Table 4 shows the forensic information mostly mentioned by the participants of group 1 (NO ID) and group 2 (ID).

Table 4: forensic information mostly mentioned to construct scenario in group 1 (NO ID) and 2 (ID).

\begin{tabular}{|l|c|c|c|}
\hline $\begin{array}{l}\text { Kind of forensic } \\
\text { information used to } \\
\text { construct scenario }\end{array}$ & $\begin{array}{l}\text { Group 1 } \\
\text { (NO ID) } \\
\text { (N=20) }\end{array}$ & $\begin{array}{c}\text { Group 2 } \\
\text { (ID) } \\
\text { (N=17) }\end{array}$ & P-value \\
\hline $\begin{array}{l}\text { Traces } \\
\text { offender 1 }\end{array}$ & 5 & 10 & $\chi^{2}(1)=4.64, \mathrm{p}<.05$ \\
\hline $\begin{array}{l}\text { Traces } \\
\text { offender 2 }\end{array}$ & 6 & 5 & n.s \\
\hline $\begin{array}{l}\text { Wounds Valerie } \\
\text { Wounds Steve }\end{array}$ & 3 & 2 & n.s. \\
\hline $\begin{array}{l}\text { No signs of damage / } \\
\text { burglary }\end{array}$ & 14 & 6 & n.s. \\
\hline House is a mess & 5 & 2 & n.s. \\
\hline Drawers searched & 7 & 4 & n.s \\
\hline Valuables present & 3 & 0 & n.s. \\
\hline Neat kitchen & 1 & $n .46, p<.05$ \\
\hline
\end{tabular}

Traces left by offender 1 were mentioned significantly more by participants of group 2 (ID) $\chi^{2}(1)=$ 4.64, $\mathrm{p}<.05$. Traces left by offender 2 were mentioned by participants in both groups. The traces were mostly mentioned as important because a person was connected to the scene, objects were perceived as a potential murder weapon or traces were perceived as suspicious. The scratches on Steves' face were mentioned by participants who formed a domestic homicide scenario. For them, it was an indication of a fight. The lack of damage and missing signs of a real burglary were mentioned more by participants of the group without ID info $\chi^{2}(1)=4.46, p<.05$. For most of these CSIs this was a reason to believe that the offender might have been known to Valerie, which was interpreted as support for the domestic homicide scenario. For a few participants it was a reason to believe the offender knocked on the door and entered the house that way. The fact that the drawers and cupboards were searched was for some participants a reason to believe there had been a break in. Other CSIs argued that the drawers were searched deviating from the usual way offenders' open drawers during a break in or that the drawers looked too uniform in their appearance to have been actually searched, an argument for the domestic homicide scenario.

A t-test was conducted to test whether those that constructed a husband scenario and those that constructed burglary scenarios differ in the amount of forensic information they use. The results show such a difference $(\mathrm{t}(35)=-3.93, \mathrm{p}<.001)$ indicating that the ones constructing more accurate scenarios (i.e. an aggravated burglary) used more forensic information. 


\subsection{Traces for analysis - Group 1 (NO ID)}

All participants were asked to select traces for analysis after they had written their scenario. They could mention six traces. Group 1 (NO ID) participants were able to choose between all traces and objects they observed at the scene. As group 2 (ID) participants already received ID information of 12 pre-selected traces, they were able to select all traces except for those 12 pre-selected traces. Therefore, we first use only group 1 (NO ID) to investigate what traces participants' need to test their hypotheses. Table 5 shows the most frequently selected traces by participants of group 1 (NO ID).

Table 5: traces selected for analysis by group 1 (NO ID).

\section{Trace selected for analysis group 1 (NO ID)}

$(\mathrm{N}=21)^{*}$

\begin{tabular}{|c|c|c|c|}
\hline Tissue with blood & 20 & Door handles & 3 \\
\hline $\begin{array}{l}\text { Window trace \& post } \\
\text { flap }\end{array}$ & 17 & $\begin{array}{c}\text { Handles drawers and } \\
\text { cupboards }\end{array}$ & 3 \\
\hline $\begin{array}{l}\text { Beer can \& cigarette } \\
\text { butt }\end{array}$ & 17 & Shoulder bag & 1 \\
\hline Stuff coffee table & 10 & Knife & 1 \\
\hline Scarf & 4 & Phone & 1 \\
\hline Traces victim & 5 & Broken glass & 0 \\
\hline Stuff on ground & 4 & & \\
\hline
\end{tabular}

The table shows that almost all participants (20) selected the tissue with blood for analysis. A reason to analyse the tissue was to obtain an ID of the person who left it. Others argued that the blood could have come from the suspect. The hand palm marks on the window and fingermarks on the post flap were selected by participants because they thought it was suspicious and could be related to a burglary, or they just wanted to obtain an ID from a third person. Most participants who selected the beer can \& cigarette for analysis constructed a domestic homicide scenario and wanted to obtain an ID. Typical objects on the coffee table, like cigarettes, a coffee cup and glasses (stuff coffee table) were also selected by participants who formed a domestic homicide scenario in order to obtain an ID.

The scarf, a possible murder weapon, was selected by only four CSIs. Six CSIs mentioned the scarf as possible murder weapon in their scenario, but only one of them selected the scarf for analysis. The other five CSIs did not select the scarf to test their hypothesis. The three CSIs who did select the scarf for analysis did not mention a possible murder weapon in their scenario, but the most common reason to analyse the scarf was to identify the offender as it was seen as a possible murder weapon. Another possible murder weapon, the shoulder bag, was only selected for analysis by one CSI. None of the other participants considered it as an important item.

Handles of doors, drawers and cupboards were only selected by a small minority of the group. The few participants selected the handles to test for other persons than the residents. The knife, which was placed as distraction by the researchers, was only selected by one CSI.

\subsubsection{Traces for analysis - Group 2 (ID)}

Participants of group 2 (ID) were also asked to select traces for analysis. They could choose all traces except for the twelve traces that already provided identification information. ${ }^{4}$ Participants in group 2 (ID) selected less traces $(\mathrm{M}=3.9, \mathrm{SD}=2.0)$ than the participants in group $1(\mathrm{M}=5.8, \mathrm{SD}=0.5)$ (NO ID)

\footnotetext{
${ }^{4}$ One participant selected the analysed traces again and was therefore excluded from this analysis.
} 
Scenario construction at the crime scene

$t(19)=3.77, p=.001$. Table 6 shows numbers of the most frequently selected traces by participants of group ID.

Table 6: most frequently selected traces by participants of group 2 (ID).

\begin{tabular}{l|c|}
\hline $\begin{array}{l}\text { Traces selected for } \\
\text { analysis }\end{array}$ & $(\mathbf{N = 1 8 )}$ \\
\hline $\begin{array}{l}\text { Handles drawers and } \\
\text { cupboards }\end{array}$ & 9 \\
\hline Door handles & 8 \\
\hline Traces victim & 8 \\
\hline Stuff on ground & 7 \\
\hline Phone & 4 \\
\hline
\end{tabular}

Handles of doors, drawers and cupboards were mostly chosen by participants who already received ID information. These CSIs wanted to know whose traces were found on the handles. Some CSIs explicitly indicated that they wanted to compare traces obtained from these handles with the profile obtained from the rapidly analysed traces showing a database-match. Both participants who created a domestic scenario as well as participants who created another perpetrator scenario selected the handles, where the majority was in the latter category. Stuff pulled out of the drawers was also selected to find a link with the rapid obtained profile or search for alien marks, both by participants with a domestic scenario and by those with another perpetrator scenario. Traces from the victim were mainly selected to search for offender traces. 


\subsection{Discussion}

Results show that introduction of identification information at the start of an investigation led to the recognition of other relevant information at the scene compared to interpreting the scene without this information, but it also led to different interpretations of identical information. Without ID information, the search for clues at the crime scene was framed by the investigative information, whereas when ID information was provided together with the investigative information, the ID information seemed to provide a framework in the search for clues. This difference in the use of information as a framework had as effect that identical information was interpreted differently and that other information was noticed. So the availability of ID information at the start of a crime scene investigation did not increase the dominance of the use of forensic information in comparison to investigative information for forming a scenario, but it did lead to different interpretations of the crime scene.

Regardless of the information, experiential knowledge of CSIs helped them to anticipate and to recognize certain signs at the crime scene. Clues such as the absence of damage, or the way a house is searched, are signs that trigger CSIs in their reconstruction of what happened. Due to their experience, CSIs have developed schemas about behaviour of offenders and the traces they may leave. These previously built interpretative schemas help drawing inferences from forensic information about the offender and his actions [18,20-22]. How these clues are interpreted appears to depend on the available information and the scenario one has in mind.

As an example, the appearance of the scene (i.e. lack of damage) mainly worked as a trigger for CSIs without ID information. More than half of those CSIs assumed it was a staged burglary because no signs of damage were discovered and the open drawers looked too uniform. They inferred that the offender must have been known to the victim and staged a burglary. Most CSIs with a burglary scenario did not mention the lack of damage, but the few who did mention it interpreted it differently. They inferred that the offender had entered the house by knocking on the door, so without damaging the front door, and argued that the drawers showed signs of a real search. Hence, experience was used to recognize relevant cues, but the received information influenced the interpretation of the clues.

In this study, the investigative information was misleading, whereas the ID information helped constructing a more accurate reconstruction of the crime, i.e. an aggravated burglary. We should be careful however with concluding that early ID information might always lead to correct interpretations. Our ground truth, an aggravated burglary, was randomly chosen and it could equally had been the other way around, i.e. a domestic homicide. Then, the ID information would have led to incorrect scenarios. In his study, Innes [32] also found that evidence based upon trace material is frequently pivotal in a scenario that is being constructed by police detectives, due to the perceived objectivity of this information. However, the relevance of the trace linked with a person in the database should constantly be taken in consideration, as the crime scene is always contaminated with unrelated traces [2]. In case of an identification coming from an unrelated trace, ID information can lead the investigation into a wrong direction. More generally, as also demonstrated by Van den Eeden et al. [14], information can help the investigation when it is correct, but lead to wrong conclusions when it is incorrect. Several studies showed similar findings for forensic experts who were influenced by contextual information in their comparisons of traces [15,33,34]. It would be useful for future research to investigate the influence of rapid identification information coming from traces unrelated with the crime.

Once convinced of a theory, the investigation might concentrate on finding incriminating evidence only $[11,12]$ although CSIs showed to be able to change their scenario when ID information suggests a different direction. Our previous study demonstrated that once ID information was provided after having constructed a provisional scenario, CSIs were able to change their scenario 
instead of interpreting the new incoming information in line with their existing scenario. ID information appeared to be of high influence on the interpretation of the crime scene, even more when provided after a provisional scenario was formed. However, the CSIs did not select the traces producing rapid ID information themselves, as they were selected by the researchers [6]. In the real world, CSIs should perceive and select the traces for analysis themselves, before they can receive ID information about the donors.

The present study showed that some forensic information was only perceived as important when ID information was provided. Only a few CSIs selected the two possible murder weapons in our case, the scarf and shoulder bag, for analysis. These traces were perceived as relevant clues by participants who received a database-match linked with the trace. Without this information, the objects were rarely recognized as potential murder weapons. This leads to the conclusion that traces are better usable in the construction of scenarios, when information about the donors is known. This may sound logical, but again, in the real world all potential traces need be perceived as important and selected for analysis, otherwise no information about donors will be provided.

The participants in our study were allowed to select six traces for further analysis, whereas CSIs in real crime cases would collect more traces in a similar kind of investigation. By giving them a restriction, we obtained insights into their thoughts about which traces were most important to test their scenario. Although well-considered, this restriction may have contributed to the finding that the two possible murder weapons were rarely selected. However, a similar finding was also demonstrated in a previous study where CSIs were asked to conduct an investigation at a mock crime scene. Only ten out of forty CSIs found a bloodstain leading to a second offender on the water tap and nine CSIs secured this blood stain [10]. We are led to the conclusion that sometimes important traces are missed during the investigation, while these traces can provide information that generates a significant twist to a scenario. The bloodstain in the previous study of De Gruijter et al. [10] led to the second offender. The identification information in the present study also showed to be of significant value as it changed the scenario into one with a different perpetrator. Although it is argued that expertise would help recognizing relevant traces [35,36], it did not help recognizing these traces. We should be aware that this may change when participants would receive more information about the victim and her injuries and when they would know for certain that she was strangled. This information would then play a significant role as intelligence in determining the relevance of the scarf or shoulder bag. However, in the real world the amount of information at the start of an investigation can also be limited and some crime scenes, for example outdoor scenes, do not offer the possibility to go back to collect traces again.

Mainly, CSIs seem to select traces for analysis in order to get verification of their scenario, and less so for falsification, although this is difficult to determine. Identical traces can be selected for analysis to test different scenarios and our data did not always uncover the underlying reasons for these decisions. CSIs whose most plausible scenario was a domestic homicide, often selected typical objects on a coffee table, in the hope to obtain an ID of the person who had drinks before the crime. It remained unclear how this information could be of use to test their scenario. Analysis information sought should be able to discriminate between scenarios, with the goal that finally one most plausible scenario survives. Our study shows that not all traces with potentially relevant information that can be used to verify a scenario are selected. The scarf is an example: although this item was mentioned as a possible murder weapon in some scenarios, not all those participants selected this item for analysis. However, we should take the limitation of six traces into account again.

It seems that CSIs are also focussed on the success rates of traces while making their decisions. The majority selected traces that have a high chance of producing a DNA profile or fingerprint, like cigarette ends, a beer can, glasses and fingermarks on the window and post flap. Handles of drawers and cupboards were chosen less often. CSIs may have assumed that the chance is 
low that a full profile of other persons than the residents would be obtained from a handle and thus the expected utility of the information conveyed by the trace.

The availability of ID information also influenced the amount of evidence that was collected.

ID information caused a reduction in the amount of traces selected for analysis. ID information already provides information about people who have been at the crime scene and may cause a feeling of satisfaction in the CSIs. Similar behaviour was shown in our previous study [10]. In that study, the availability of multiple rapid database-matches with one person made some of the CSIs stop analysing new traces. This strategy has no consequences when the database match is of the actual offender, but could lead to problems when other persons are actually involved.

Although gaining insights into the decision making of CSIs is only possible within controlled settings, this method obviously has its limitations too (see also [6]). The most evident one is the fact that investigating a crime scene in a computerized setting cannot be compared with investigating a scene in the real world. All participants were asked to what extent it had been possible to properly answer the questions on the basis of the computerized scene and the photos, using a 7-point Likert scale. CSIs scored a 3.5, showing that they had some difficulty interpreting the artificial scene as a real crime scene. Also, none of the participants had any experience with mobile technologies for rapid DNA or fingerprint analyses. However, we believe this method is suitable for the purpose of this study, namely providing meaningful insights into thinking processes and decision making of CSIs, more specifically their decision making with the presence of rapid identification information. It gives us more insight about the kind of information CSIs use to construct a scenario and the inferences drawn from it. An aspect that may have influenced the participants' selection for traces is the absence of the body of the victim, usually an important source of information. Such information could have placed some objects and traces in context and potentially could have changed the selection of traces for analysis. Future studies could choose to incorporate different pieces of information for the participants to reconstruct the event in order to make the study more corresponding with the real world and to study the process of trace selection more thoroughly.

Another limitation is the small sample size and the rather large standard deviations within the conditions, which makes it difficult to demonstrate differences between the conditions. CSIs maintain different methods and strategies leading to large variations within the groups [10,37]. Replication of our study would be welcome.

This study shows that the availability of ID information leads to the recognition of different clues at the crime scene and to different interpretations of identical information, depending on the kind of information available and the scenario one has in mind. Without identification information, the interpretation of the crime scene is mostly in line with the investigative information. Experience helps recognition of relevant clues, as CSIs use interpretative schemas to draw inferences from forensic information about the offender and his actions, but the available information determines how this information is interpreted. In this case, CSIs with accurate crime scenarios used more forensic information, but our ground truth, an aggravated burglary, was randomly chosen and it could equally had been different, whereby the ID information would have led to incorrect scenarios. We should be aware of the fact that crime scenes are always contaminated with unrelated traces and therefore the power of rapid identification at the crime scene needs further investigation. The finding that some forensic information was only perceived as important when ID information was provided, leads to the conclusion that important traces may be missed during an investigation. In the real world all traces need to be perceived as important and selected for analysis, as otherwise no information about donors can be found. The question arises how often in the real world traces are perceived as unimportant and left at the crime scene. This issue deserves further empirical study. It may result in producing valuable information that can be used to make CSIs aware of biased decision making, as well as it can be 
Scenario construction at the crime scene

helpful when educating police about the power of rapid identification technologies and their associated risks. 


\section{References}

[1] S. Bitzer, N. Albertini, E. Lock, O. Ribaux, O. Delémont, Utility of the clue - From assessing the investigative contribution of forensic science to supporting the decision to use traces, Sci. Justice. 55 (2015) 509-513. doi:10.1016/j.scijus.2015.05.005.

[2] O. Delémont, E. Lock, O. Ribaux, Forensic Science and Criminal Investigation, in: G. Bruinsma, D. Weisburd (Eds.), Encycl. Criminol. Crim. Justice, Springer New York, New York, NY, 2014: pp. 1754-1763. doi:10.1007/978-1-4614-5690-2_145.

[3] J.M. Butler, The future of forensic DNA analysis, Philos. Trans. R. Soc. B. 370: 20140 (2015). doi:http://dx.doi.org/10.1098/rstb.2014.0252.

[4] S. Jovanovich, G. Bogdan, R. Belcinski, J. Buscaino, D. Burgi, E.L.R. Butts, K. Chear, B. Ciopyk, D. Eberhart, O. El-sissi, H. Franklin, S. Gangano, J. Gass, D. Harris, L. Hennessy, A. Kindwall, D. King, J. Klevenberg, Y. Li, N. Mehendale, R. Mcintosh, B. Nielsen, C. Park, F. Pearson, R. Schueren, N. Stainton, C. Troup, P.M. Vallone, M. Vangbo, T. Woudenberg, D. Wyrick, S. Williams, Developmental validation of a fully integrated sample-to-pro fi le rapid human identi fi cation system for processing single-source reference buccal samples, Forensic Sci. Int. Genet. 16 (2015) 181-194. doi:10.1016/j.fsigen.2014.12.004.

[5] J. Kurpershoek, Indicatief onderzoek: steeds sneller, Blauw. (2009) 32-35.

[6] M. De Gruijter, C. Nee, C. De Poot, Identification at the crime scene: the sooner, the better? Constructing scenarios with rapid identification information at the crime scene, Sci. Justice. (2017). doi:http://doi.org/10.1016/j.scijus.2017.03.006.

[7] N. Pennington, R. Hastie, The story model for juror decision making, in: R. Hastie (Ed.), Insid. Jury Psychol. Juror Decis. Mak., Cambridge University Press, Cambridge, 1993: pp. 192-221.

[8] W.A. Wagenaar, P.J. van Koppen, H.F. Crombag, Anchored narratives: The psychology of criminal evidence, St Martins's Press, 1993.

[9] A. Jamieson, A rational approach to the principles and practice of crime scene investigation: I. principles, Sci. Justice. 44 (2004) 3-7.

[10] M. De Gruijter, C.J. De Poot, H. Elffers, Reconstructing with trace information: does rapid identification information lead to better crime reconstructions?, J. Investig. Psychol. Offender Profiling. 61 (2016) 43-51. doi:10.1002/jip.1471.

[11] H.F.M. Crombag, Over tunnelvisie, in: J.W. van Koppen, Peter J. Merckelbach, H.; Jelicic, M.; de Keijser (Ed.), Reiz. Met Mijn Rechter, Uitgeverij Kluwer, Deventer, 2010: pp. 387-399.

[12] R.S. Nickerson, Confirmation bias: A ubiquitous phenomenon in many guises, Rev. Gen. Psychol. 2 (1998) 175-220. doi:10.1037/1089-2680.2.2.175.

[13] I. Dror, Cognitive neuroscience in forensic science : understanding and utilizing the human element, Philos. Trans. R. Soc. B. 370 (2015).

doi:http://dx.doi.org/10.1098/rstb.2014.0255.

[14] C.A.J. Van den Eeden, C.J. De Poot, P.J. Van Koppen, Forensic expectations: Investigating a crime scene with prior information, Sci. Justice. 56 (2016) 475-481. doi:10.1016/j.scijus.2016.08.003.

[15] I. Dror, D. Charlton, A.E. Péron, Contextual information renders experts vulnerable to making erroneous identifications, Forensic Sci. Int. 156 (2006) 74-78. doi:10.1016/j.forsciint.2005.10.017.

[16] I. Dror, R. Stoel, Cognitive Forensics: Human cognition, contextual information, and bias, in: D. Bruinsma, G.; Weisburg (Ed.), Encycl. Criminol. Crim. Justice, Springer New York, New York, 2014: pp. 353-363.

[17] O. Ribaux, A. Girod, S.J. Walsh, P. Margot, S. Mizrahi, V. Clivaz, Forensic 
intelligence and crime analysis, Law, Probab. Risk. 2 (2003) 47-60.

[18] D. Kahneman, Thinking fast and slow, Penguin, 2012.

[19] M.T.. Chi, R. Glaser, E. Rees, Expertise in problem solving, in: R. Stenberg (Ed.), Adv. Psychol. Hum. Intell., Erlbaum, Hillsdale, NJ, 1982: pp. 7-75.

[20] C. Nee, T. Ward, Review of expertise and its general implications for correctional psychology and criminology, Aggress. Violent Behav. 20 (2015) 1-9. doi:10.1016/j.avb.2014.12.002.

[21] J. Shanteau, How much information does an expert use? Is it relevant?, Acta Psychol. (Amst). 81 (1992) 75-86. doi:10.1016/0001-6918(92)90012-3.

[22] G.A. Klein, A recognition-primed decision (RPD) model of rapid decision making, Ablex publishing corporation New York, New York, 1993.

[23] M.J. Saks, D.M. Risinger, R. Rosenthal, W.C. Thompson, Context effects in forensic science: A review and application of the science of science to crime laboratory practice in the United States, Sci. Justice. 43 (2003) 77-90.

[24] I. Dror, The paradox of human expertise: why experts get it wrong., in: N. Kapur (Ed.), Parad. Brain, Cambridge University Press, Cambridge, 2011: pp. 177-188. doi:10.1007/978-1-61779-095-9.

[25] K.R. Popper, The logic of scientific discovery, Hutchinson, London, 1986.

[26] A.A. Mapes, A.D. Kloosterman, C.J. de Poot, DNA in the Criminal Justice System: The DNA Success Story in Perspective, J. Forensic Sci. 60 (2015) 851-856. doi:10.1111/1556-4029.12779.

[27] K.J. Strom, M.J. Hickman, Unanalyzed evidence in law- enforcement agencies, Criminol. Public Policy. 9 (2010) 381-404.

[28] M. Lynch, Science, truth, and forensic cultures: The exceptional legal status of DNA evidence, Stud. Hist. Philos. Biol. Biomed. Sci. 44 (2013) 60-70. doi:10.1016/j.shpsc.2012.09.008.

[29] I. Dror, Science and Justice The ambition to be scientific: Human expert performance and objectivity, Sci. Justice. 53 (2013) 81-82. doi:10.1016/j.scijus.2013.03.002.

[30] S.M. Kassin, I.E. Dror, J. Kukucka, The forensic confirmation bias: Problems, perspectives, and proposed solutions, J. Appl. Res. Mem. Cogn. 2 (2013) 42-52. doi:10.1016/j.jarmac.2013.01.001.

[31] J.R. Landis, G.G. Koch, An Application of Hierarchical Kappa-type Statistics in the Assessment of Majority Agreement among Multiple Observers, Biometrics. 33 (1977) 363-374.

[32] M. Innes, Investigating murder: Detective work and the police response to criminal homicide, Oxford University Press, Oxford, 2003.

[33] I. Dror, G. Hampikian, Subjectivity and bias in forensic DNA mixture interpretation, Sci. Justice. 51 (2011) 204-208. doi:10.1016/j.scijus.2011.08.004.

[34] N.K.P. Osborne, S. Woods, J. Kieser, R. Zajac, Does contextual information bias bitemark comparisons ?, Sci. Justice. 54 (2014) 267-273. doi:10.1016/j.scijus.2013.12.005.

[35] S.F. Kelty, R. Julian, J. Robertson, Professionalism in Crime Scene Examination : The Seven Key Attributes of Top Crime Scene Examiners, Forensic Sci. Policy Manag. 2 (2011) 175-186. doi:10.1080/19409044.2012.693572.

[36] D. Wyatt, Practising crime scene investigation: trace and contamination in routine work, Polic. Soc. An Int. J. Res. Policy. 24 (2014) 443-458. doi:10.1080/10439463.2013.868460.

[37] M. De Gruijter, C.J. De Poot, H. Elffers, The Influence of New Technologies on the Visual Attention of CSIs Performing a Crime Scene Investigation, J. Forensic Sci. 61 (2016) 43-51. 
Scenario construction at the crime scene 